\title{
Entrevista com o Secretário de Saúde de Londrina (PR), Sílvio Fernandes da Silva, sobre questões de implantação do SUS
}

\author{
Interview with the Municipal Secretary of Health \\ of Londrina, Paraná, about issues related to the \\ implantation of the Unified Health System (SUS)
}

Doutor em saúde pública pela USP e atual secretário municipal de saúde de Londrina, Sílvio Fernandes tem sido, em suas atividades profissionais, um ator fundamental do processo de descentralização e de municipalização do setor. Foi em sua primeira gestão como secretário, há oito anos, que Londrina passou a compor os municípios em gestão plena, fato que enaltece a qualidade de sua liderança no setor. Além de ser um executivo competente, Sílvio é também um professor e pensador. Isso se pode constatar na leitura de dois livros de sua autoria, A construção do SUS a partir do município e municipalização da Saúde (1996); e Poder local: sujeitos, atores e políticas (2001), nos quais realiza uma importante reflexão sobre o processo de construção da política universalizadora de direitos em saúde e de um novo modelo assistencial. Nesta entrevista, os leitores encontrarão uma opinião qualificada e balizadora, própria de quem fala a partir da experiência pensada, de forma ao mesmo tempo crítica e otimista.
C\&SC Desde o início da década de 1990 se intensificou a descentralização do setor saúde. Como secretário de saúde e como estudioso do tema, como o senhor avalia esse processo na sua complexidade, destacando os pontos mais positivos e os mais negativos?

SF De fato, a descentralização da saúde teve um grande impulso no início da década de 1990. Isto ocorreu, especialmente, em virtude da descentralização na gestão dos recursos federais, que passaram a ser transferidos do Fundo Nacional para os Fundos Municipais de Saúde. Este processo, que começou com as gestões semiplenas na primeira metade daquela década, expandiu-se mais ao final com as gestões plena da atenção básica e plena do sistema municipal de saúde. Atualmente mais de $60 \%$ dos recursos federais destinados à assistência são transferidos "fundo a fundo" para os municípios.

$\mathrm{Na}$ análise da descentralização do setor saúde é necessário, no entanto, considerar as inúmeras contradições que acompanharam sua implementação. Se por um lado cumpriu-se um preceito constitucional do SUS de transferir recursos financeiros e o poder de decidir sobre sua aplicação aos atores locais - conselhos de saúde e governantes -, por outro é importante considerar que isto foi acompanhado de inúmeros constrangimentos e dificuldades. Em síntese, os governantes locais assumiram novas responsabilidades na área da assistência sem contraparti- 
da suficiente de recursos financeiros e também sem um adequado planejamento que lhes permitissem gerenciar a transição para o novo modelo assistencial. Um exemplo dessa situação é a política de recursos humanos do SUS. Em virtude da inexistência de uma política de RH que desse conta da complexidade do processo descentralizatório, não temos, por exemplo, como repor servidores federais ou estaduais municipalizados que se exoneram, por falta de recursos financeiros e por constrangimentos impostos pela Lei de Responsabilidade Fiscal. A este problema se somam outros, como o perfil dos profissionais disponíveis e plano de carreira inadequados.

Tivemos, no entanto, muitos aspectos positivos com a descentralização. Acho que a incorporação de novos atores, anteriormente destituídos de qualquer poder, ao processo de decisão das políticas locais foi um dos mais marcantes. $\mathrm{O}$ fato de termos milhares de conselhos municipais e inúmeros conselhos gestores de unidades, e de mobilizarmos dezenas de milhares de conselheiros que discutem a saúde por todo o país, está se constituindo em um grande patrimônio do SUS. Mesmo que esta participação nem sempre tenha possibilidade de interferir com efetividade na formulação e implementação das políticas de saúde, por fatores ligados às diferentes realidades locais, é um processo de participação direta da população que está em crescimento. Além de ampliar a consciência dos direitos à saúde, por estimular o debate e interferir positivamente na agenda política local, tem estimulado uma fiscalização mais adequada dos recursos públicos do setor.

Queria me posicionar também sobre a eficiência e eficácia das gestões descentralizadas. Este é um tema que tem sido tratado por diferentes atores do SUS, e às vezes de forma apaixonada e maniqueísta. Os que adotam com muito rigor o slogan que ficou famoso no movimento municipalista da saúde "Municipalização é o caminho", e que foi, aliás, tema da IX Conferência Nacional de Saúde em 1992, freqüentemente exageram as conquistas do movimento descentralizatório e procuram enfatizar apenas seus aspectos positivos. Por outro lado há os que desvalorizam ou desconsideram importantes avanços da descentralização da saúde e consideram que a municipalização da forma como foi conduzida levou à criação de "feudos municipais", onde municípios maiores "fecham as portas" aos menores, inexistindo mecanismos que possam regular o acesso dos usuários de forma a garantir a assistência.
Essas visões polarizadas, em meu ponto de vista, reduzem a análise. A autonomia de gestão foi acompanhada de avanços na gestão da saúde, conforme mostram vários estudos de caso. Diversos municípios aproveitaram a municipalização da saúde para implementar ações inovadoras, modernizar o gerenciamento dos serviços e aperfeiçoar os mecanismos de avaliação, controle e auditoria. Não dá para negar, por outro lado, a existência de algumas gestões municipais ineficazes e sem direcionalidade, nas quais a ampliação da autonomia de gestão, por diferentes fatores inerentes ao processo político local, não foi utilizada como uma oportunidade de aperfeiçoamento das políticas locais de saúde.

C\&SC Existem teorias e avaliações que enfatizam algumas críticas importantes ao processo de descentralização. Dizem, de um lado, que ele encarece muito o custo dos serviços de saúde; de outro lado, alguns consideram que a descentralização, na verdade, é uma desresponsabilização do governo federal em relação aos problemas de saúde da população. O que o senhor pensa a esse respeito?

SF A descentralização encarece o custo quando os gestores locais ampliam de forma desordenada a oferta pública de serviços, sem levar em conta elementos básicos da boa gestão pública, tais como eficiência econômica e a busca de economia de escala na criação de novos serviços.

Minha impressão é que isto pode acontecer por dois motivos principais. O primeiro deles em virtude da redução da oferta privada em algumas áreas assistenciais para as quais a remuneração da tabela de procedimentos não é atrativa para os prestadores privados. Diante desta situação, muitos gestores com dificuldade para regular e manter a oferta privada e pressionados pela demanda não atendida criam serviços públicos nem sempre eficientes - mesmo que necessários - tais como serviços de eletroencefalografia, ultra-sonografia, etc. Inserem-se nesta categoria também boa parte dos serviços oferecidos pelos consórcios intermunicipais de saúde - especialmente na área que denominamos de média complexidade como consultas e exames especializados - para os quais a remuneração do SUS se tornou muito baixa por falta de reajustes. Outro motivo para a elevação dos custos, suponho que menos freqüente que o anterior, seria a expansão de serviços não prioritários atendendo a interesses de grupos 
locais. Por exemplo, credenciam-se, sem necessidade, leitos hospitalares ou serviços ambulatoriais de média ou alta complexidade.

O primeiro dos motivos explicitados acima mostra um lado perverso da descentralização e de certa forma representa uma desresponsabilização dos governos federal e estadual para com os problemas de saúde da população. Eu diria que representa falta de solidariedade com os municípios no financiamento da saúde. Ou seja, a transferência de responsabilidades trouxe o conflito do não atendimento adequado à população para as arenas políticas locais. Premidos pela pressão social decorrente da demanda não atendida, e sem auxilio adequado no financiamento dos outros níveis de governo, os gestores locais freqüentemente agem como bombeiros. Como nesta situação de governabilidade restrita nem sempre utilizam as estratégias de gestão mais adequadas, acabam por regular mal a relação com os prestadores privados e por ampliar desordenadamente a oferta pública, encarecendo custos. É necessário destacar, no entanto, que estes problemas, em sua essência, existem em virtude de políticas nacionais historicamente inadequadas tanto de financiamento quanto na relação que se estabeleceu com os prestadores privados, que obtêm reajustes diferenciados para as áreas que mais lhes interessam atender. Ocorrem também devido à falta de capacitação dos gestores locais, tornando-os freqüentemente mais vítimas do que responsáveis por essa situação.

Por fim, quero reafirmar que a preocupação com o custo dos serviços no SUS é bastante pertinente e atual. Este assunto está sendo tratado na NOAS (Norma Operacional da Assistência) em suas versões 2001 e 2002, que preconiza instalação de serviços de maior complexidade apenas quando atenderem requisitos de economia de escala. A instalação de um serviço público de ultra-sonografia, ou mesmo o credenciamento de um prestador privado, por exemplo, em tese não poderá ocorrer em municípios muito pequenos a não ser que seja referência para outros municípios vizinhos no processo de regionalização proposto pela NOAS. Se a esta reorganização do modelo de assistência forem instituídas medidas que ampliem a oferta visando atender necessidades não supridas, poderemos ter avanços nesta área.

C\&SC Quais são os pontos cruciais para que uma descentralização seja bem-sucedida?

SF Penso que as possibilidades da descentralização dependem do contexto econômico e po- lítico em que ocorrem. No Brasil, considerando-se o momento histórico em que ocorreu, este processo está sendo impulsionado por movimentos políticos contraditórios. Por um lado é uma das principais diretrizes do movimento sanitário, para o qual a descentralização contribuiria para transferência de poder aos atores locais, para aperfeiçoar a democracia e para melhor utilizar os recursos públicos. Por outro, a descentralização coincidiu, em nosso país, com a implementação das políticas de ajuste fiscal e de reforma neoliberal do Estado, ocorridas a partir da década de 1990, e que tem sido acompanhada de restrição de direitos sociais e de fragmentação das demandas para os espaços locais.

A descentralização, conceitualmente compreendida segundo a racionalidade do movimento sanitário, se manteve numa posição contra-hegemônica, não se consolidando efetivamente como política de Estado. O ajuste fiscal, por outro lado, teve predominância e se tornou hegemônico nas grandes arenas políticas, que decidem o rumo das macropolíticas econômicas. Apesar disso, acho que o movimento sanitário teve inúmeras conquistas. Um exemplo disso, o mais recente, foi a aprovação da EC 29 (Emenda Constitucional no 29), que, ao vincular percentuais mínimos dos recursos públicos arrecadados para a saúde, procura impor limites à ação das políticas de ajuste em nosso setor.

Para que a descentralização amplie suas possibilidades e seja mais bem-sucedida é necessário, por um lado, que os atores políticos do movimento sanitário não percam essa dimensão mais ampla dos desafios políticos para a implementação do SUS. Ou seja, só ampliaremos direitos sociais se tivermos políticas, no seu sentido macroeconômico, menos perversas para as políticas sociais. Por outro, existem desafios próprios da operacionalização da descentralização que também devem ser superados por nós. Para este segundo ponto é necessário acreditar na potencialidade e na importância da delegação de poder ao chamado poder local. Eu me preocupo com manifestações de descrédito que às vezes ouço em relação às potencialidades do poder local, por parte de aliados do movimento sanitário. É um equívoco interromper o processo descentralizatório e recentralizar determinadas ações. Nosso desafio é melhorar a descentralização, e isto implica aperfeiçoar a democratização do processo decisório e a capacitação dos gestores locais na implementação das políticas do SUS. 
C\&SC Que funções ou que serviços do sistema de saúde, o senhor considera que não devam ser descentralizados?

SF Existem críticas sobre o esvaziamento do papel das secretarias estaduais de saúde a partir da implementação das NOB/93 e 96. Concordo com elas. Passamos por um rápido período de "estadualização da saúde" na década de 1980, no qual as secretarias estaduais assumiram responsabilidades diretas na assistência e na formulação de políticas, assumindo um papel que antes cabia à União. Em seguida, com a municipalização, foram transferidas as responsabilidades assistenciais aos municípios. Isso foi feito de uma forma que fez com que as secretarias estaduais ficassem enfraquecidas tanto no seu papel assistencial, como no de regulação e de formulação de políticas.

É necessário que haja maior inserção e fortalecimento das secretarias estaduais na implementação do SUS. E para isso, devem recuperar seu papel de regulação na assistência de maior complexidade, especialmente na garantia de acesso de usuários aos serviços localizados em outros municípios. Devem também melhor desenvolver políticas de competência de governos estaduais, tais como controle de sangue e hemoderivados, endemias, redes de emergência etc. Além disso, devem apoiar solidariamente os municípios e a União no financiamento da assistência, procurando instituir mecanismos que contribuam com a equidade, como, aliás, alguns estados estão fazendo nos últimos anos. Sobre este último ponto, vejo com preocupação a relutância de algumas secretarias estaduais de saúde em assumir responsabilidades nesta área, sob argumentos de que historicamente foram atribuições do governo federal.

Quanto à União, tem responsabilidades no âmbito do que costumamos chamar macropolíticas de saúde, ou seja, nas grandes estratégias. Constituem ações que devem ser obviamente centralizadas, tais como os grandes eixos da política farmacêutica, o combate a endemias prioritárias, a definição de diretrizes na relação pública com o setor privado etc.

É necessário estabelecer limites entre as competências dos três níveis de governo e, a meu ver, este é um desafio não superado. Temos dificuldades no estabelecimento destes limites e, nos últimos anos, observa-se, cada vez mais, centralização de ações que reduzem a autonomia local. Cito dois exemplos bem atuais: critérios muito rígidos para transferência de incentivos federais aos municípios (para controle de endemias, PACS/PSF etc.) e recente centralização na gestão dos recursos do Fideps (Fundo de Incentivo ao Ensino, Pesquisa e Extensão) dos hospitais universitários, retirando dos gestores estaduais e municipais importante instrumento de gestão.

C\&SC A seu ver, quais são as vantagens da gestão local de saúde? O senhor considera que a participação social mais ampla e dos Conselhos de Saúde, em particular, agrega mais qualidade e mais responsabilidade aos processos locais de saúde?

SF A gestão local é a única que incorpora sujeitos ao processo decisório e amplia as possibilidades de o poder local interferir no direcionamento das políticas de saúde. Em uma sociedade desigual como a nossa (o quarto país mais desigual de um rol de 173 países, segundo recente levantamento), na qual não só a renda, mas também o poder de decisão estão muito centralizados, incorporar sujeitos populares - usuários e trabalhadores de saúde dos Conselhos de Saúde, por exemplo - no processo de decisão é, por si só, um avanço. Além disso, os governantes locais passaram a responsabilizar-se por elaborar planos de saúde viáveis e factíveis, pois, caso contrário, teriam dificuldades de ter seu poder legitimado perante as outras instâncias de governo e perante a própria população.

Utilizando o pensamento de Carlos Matus, particularmente sua proposição de triângulo de governo, para analisar a dimensão dos desafios da gestão local, penso que a descentralização bem-sucedida, com efetiva delegação de poder, amplia a governabilidade dos gestores. Se construírem bons projetos de intervenção visando melhorar a qualidade do sistema de saúde, e tiverem competência e domínio das técnicas para sua implementação, poderão avançar significativamente na gestão da saúde.

C\&SC Que futuro o senhor vê para o SUS como um sistema e como resposta às necessidades de saúde da população brasileira?

SF O SUS é produto de uma política social inclusiva, que adota princípios doutrinários ousados para estes momentos de hegemonia neoliberal, tais como universalidade, eqüidade e participação popular. Costumo comentar, nas reflexões com meus alunos e companheiros de trabalho, como seria a década de 1990 para a saúde se não tivéssemos tido o caminhar da construção do SUS. Que sistema de saúde teríamos se não tivesse havido essa ampla mobilização so- 
cial procurando reformar o Estado visando incorporar amplos direitos constitucionais no nosso setor da saúde? Possivelmente o sistema público se restringisse a um modelo de pacotes básicos, bem ao gosto de organismos financeiros internacionais, e ao atendimento em hospitais públicos e ambulatórios públicos inadequadamente estruturados.

Temos, no entanto, apesar e por causa do SUS, incontáveis desafios a superar. Alguns amplos, não propriamente setoriais, que dizem respeito às condições gerais de vida e, indiretamente de saúde, especialmente o desemprego, a violência urbana e a desigualdade na distribuição de renda. Estes fatores sociais e econômicos estão contribuindo para mudar de forma muito rápida o perfil nosológico da população. Para citar um exemplo, me lembro que há oito anos, era secretário de saúde de Londrina e comemorávamos a redução da mortalidade infantil e das doenças infecto-contagiosas. Por outro lado passávamos a nos preocupar, além de doenças crônico-degenerativas e câncer, com mortes no trânsito. Esta última, particularmente, passou a ter destaque em nossa agenda de prioridades. Hoje, novamente como secretário dessa cidade, vejo que a população, nas conferências de saúde e nas reuniões de Conselhos Locais, reivindica, muito mais freqüentemente do que antes, equipamentos públicos para tratamento de dependentes de drogas e proteção contra assaltos e violência. Os homicídios, desde o ano passado, passaram a superar de forma expressiva as mortes no trânsito em nosso município, cidade que, aliás, há não muito tempo era usada como exemplo de segurança e tranqüilidade pelos que moravam nas grandes metrópoles.

Outros desafios são inerentes ao nosso setor da saúde. Alguns estão sendo superados, como a política de prevenção e tratamento da AIDs e a redução de doenças imunopreveníveis, por exemplo. Persistem, no entanto, inúmeras deficiências na área da assistência, no combate a endemias, entre outras, que fazem com que o SUS, muito compreensivelmente, ainda seja, no imaginário de boa parte da população, um "sistema para pobres" e não uma conquista do cidadão. Apesar disso, sou otimista com o futuro e tenho convicção que estamos e continuaremos avançando na construção do Sistema Único de Saúde no Brasil. 